\title{
Caracterização de metástases ósseas em neoplasias ocultas e neoplasias previamente diagnosticadas
}

\author{
Comparison of the incidence of bone metastases in occult neoplasms versus \\ previously diagnosed cancers
}

\author{
Catarina Lucas, Inês Vidal, Joana Costa, Pedro Ribeiro, Adriano Rodrigues \\ Serviço de Medicina Interna B. Hospital Geral. Centro Hospitalar e Universitário de Coimbra
}

\section{Resumo}

Introdução: A metastização óssea associa-se, geralmente, a mau prognóstico, com evidência de doença neoplásica avançada. Este estudo caracteriza uma amostra de doentes com metastização óssea e neoplasia primária conhecida, comparando com doentes sem neoplasia diagnosticada previamente.

Material e métodos: Estudo observacional retrospectivo, onde foram incluídos doentes com diagnóstico de "neoplasia óssea secundária" ou "metástases ósseas", admitidos no nosso hospital, de 2009 a 2013. Analisados os dados de doentes com metástases ósseas com neoplasia primária conhecida ou oculta.

Resultados: Incluídos 94 doentes, média de idades de 69ะ12. 66anos, $68 \%$ do sexo masculino. Os sintomas apresentados eram principalmente dorso-lombalgia (34\%) e défice de força muscular dos membros (15\%). Eám $42 \%$ dos doentes, existia previamente 0 diagnóstico de neoplasia. A coluna vertebral constituiu o principal local de metastização. Em 22\% dos doentes não se identificou a neoplasia primária. A taxa de mortalidade durante o internamento foi de 14\%, e no follow-up após um ano de 31\%. Discussão: No estudo efectuado, verifica-se que a mortalidade à data de alta do internamento em doentes com neoplasia conhecida é superior à dos doentes com neoplasia indeterminada, 0 que não se verifica no follow-up a 1 ano. Pode considerar-se que os doentes com neoplasia previamente conhecida podem apresentar metastização óssea mais tardia, e assim, com pior prognóstico.

Conclusão: A disseminação tumoral com expressão através da metastização relaciona-se com um agravamento do prognóstico no follow-up.

Palavras-chave: metástases ósseas, coluna vertebral, neoplasia

\section{Introdução}

0 osso constitui o principal local de metastização na patologia tumoral. A metastização óssea pode ocorrer associada a diversos tipos de tumores, sendo, no entanto, mais frequente na neoplasia da mama, próstata e pulmã $0^{1}$. As características da metastização óssea, nomeadamente a osteossíntese e a osteólise, podem ser características de um determinado tipo de tumor. No entanto, alguns estudos demonstraram a existência de mais de um tipo de lesão óssea, com características osteolíticas e osteoblásticas em doentes com neoplasia da próstata². Este tipo de lesões ósseas podem ter diversas complicações associadas, tais como compressão medular, hipercalcémia, fracturas patológicas e dores ósseas severas ${ }^{1}$.

As metástases ósseas podem ocorrer em praticamente todos os ossos. No entanto, o local mais frequente é a coluna vertebral, seguido pelos ossos constituintes da bacia, os arcos costais e o fémur ${ }^{3}$.

\section{Abstract}

Introduction and aims: The bone metastases usually have a bad prognosis, with evidence of advanced malignancy. This study evaluates the characteristics of patients with bone metastases and known primary neoplasia, comparing to those without previous diagnosed neoplasia.

Material and methods: A retrospective observational study, was conducted to gather patients with diagnosis of "secondary bone cancer" or "bone metastasis", admitted to our hospital, from 2009 to 2013. Data from patients with known primary neoplasia, comparing to those with unkown origin neoplasia, were analyzed.

Results: Ninety four patients were included, mean age 69+12. 66 years, $68 \%$ male. The symptoms were mostly back pain (34\%) and limbs muscle strength deficits (15\%). In $42 \%$ of them, there was a previous diagnosis of neoplasia. The spine was the primary site of metastasis. In $22 \%$ of patients, the primary tumor was not identified. The mortality rate during hospitalization was $14 \%$, and $31 \%$ at one year follow-up.

Discussion: In the study carried out, mortality at the end of hospitalization in patients with known neoplasia was higher than that of the patients with unkown neoplasia, which is not maintained at one year follow-up. Therefore, later presentation as bone metastasis in patients with known neoplasia, could confer a worse prognosis.

Conclusion: The tumor spread with presentation through bone metastases, appears to be associated with a worse prognosis at follow-up. Keywords: bone metastasis, spine, neoplasia

0 microambiente do osso é ideal para a progressão tumoral e, desta forma para a metastização, dada a sua vascularização e a produção de moléculas de adesão, sendo também uma fonte de moléculas de angiogénese e reabsorção $0^{4}$.

Com este estudo, pretende-se caracterizar uma amostra de doentes internados com o diagnóstico de metastização óssea, assim como comparar um grupo de doentes com neoplasia previamente conhecida com um grupo de doentes sem neoplasia identificada. Considerou-se, assim, importante a avaliação das metástases ósseas mais frequentes e em que tipos de neoplasias ocorreram. Em diversos estudos, concluiu-se que a presença de metástases ósseas em doente com tumor primário de local não determinado, apresentaria um pior prognóstico, assim como taxas de mortalidade aos 5 anos mais elevadas 5 .

\section{Material e métodos}

Estudo observacional retrospectivo, incluídos 94 doentes com diagnóstico de "neoplasia óssea secundária" ou "me- 
tástases ósseas", no período de 2009 a 2013, internados nos diversos serviços do Hospital Geral do Centro Hospitalar e Universitário de Coimbra. Foram analisados os dados de doentes com metástases ósseas com neoplasia primária conhecida ou oculta.

Foram recolhidos e analisados os seguintes dados: sexo, idade, serviço responsável, clínica, tempo de evolução das queixas, existência prévia de neoplasia conhecida, localização das metástases, tipo de lesões (osteolíticas e/ou osteoblásticas), follow-up após 1 ano. Para a determinação do tipo de lesões ósseas foram analisados relatórios de exames complementares de diagnóstico ou observação e análise de radiografias, tomografia computorizada ou ressonância magnética.

Realizou-se uma análise descritiva dos dados, com expressão em frequência e/ou percentagem.

Todos os doentes analisados mantiveram seguimento após o diagnóstico, o que permitiu o follow-up após a alta do internamento.

Os dados foram analisados segundo o programa SPSS statistics versão 22. $0 \circledR$.

\section{Resultados}

Foram analisados no total, 94 doentes, com uma média de idades de $69 \pm 12.66$, sendo $68 \%$ do sexo masculino e $32 \%$ do sexo feminino. Relativamente ao Serviço responsável, $25 \%$ dos doentes foram internados no Serviço de Medicina Interna, 25\% na Neurocirurgia, 17\% na Urologia, 16\% na Pneumologia e $5 \%$ na Cirurgia.

Os sintomas referidos eram principalmente dorso-lombalgia (34\%) e défice de força muscular dos membros (15\%), seguido de astenia (13\%) (Tabela 1). Em termos de tempo de evolução dos sintomas, 50 doentes apresentavam queixas com menos de um mês de evolução. Os sintomas encontravam-se relacionados com o local de metastização em 63 doentes. Em cerca de 42\% dos doentes, já existia 0 diagnóstico prévio de neoplasia, sendo que $20.5 \%$ apresentavam o diagnóstico de neoplasia da próstata e 12. 8\% de neoplasia do pulmão.

A coluna vertebral constituiu o principal local de metastização (55 doentes, 59\%), seguido pela bacia (36 doentes, $34 \%$ ) (Tabela 2). Destas, as lesões localizadas na coluna vertebral encontravam-se mais associadas ao tumor do pulmão e, curiosamente, da próstata, enquanto as lesões da bacia estavam maioritariamente associadas à neoplasia da próstata e cólon. As lesões osteolíticas foram as mais diagnosticadas (68\%). No grupo de doentes com lesões osteolíticas, cerca de $25 \%$ dos doentes apresentava o diagnóstico de neoplasia do pulmão, $11 \%$ de neoplasia da próstata e 8\% de neoplasia da mama; $7 \%$ dos doentes com lesões osteolíticas permaneceu com o diagnóstico de neoplasia oculta à data de alta do internamento. Relativamente aos doentes com lesões osteoblásticas, 45\% foram diagnosticados com neoplasia da próstata, enquanto 18\% apresentavam o diagnóstico de neoplasia oculta. No entanto, em cerca de 5\%
Tabela 1. Incidência dos sintomas iniciais nos doentes analisados

\begin{tabular}{|l|c|}
\hline Sintomas & Incidência (\%) \\
\hline Dor dorsal e/ou lombar & $34 \%$ \\
\hline Diminuição da força muscular & $15 \%$ \\
\hline Astenia & $13 \%$ \\
\hline Dor abdominal & $10.6 \%$ \\
\hline Dispneia e/ou tosse & $10.6 \%$ \\
\hline Perda ponderal & $7.5 \%$ \\
\hline Anorexia & $5.3 \%$ \\
\hline Febre & $4 \%$ \\
\hline
\end{tabular}

Tabela 2. Locais das lesões ósseas*

\begin{tabular}{|l|c|}
\hline Local & Incidência (n) \\
\hline Coluna vertebral & 55 \\
\hline Bacia & 34 \\
\hline Grelha costal & 17 \\
\hline Crânio & 14 \\
\hline Fémur & 12 \\
\hline Úmero & 4 \\
\hline
\end{tabular}

*0 número total é superior ao número total de doentes analisados no estudo dado a possibilidade de co-existência de mais de um local de lesão óssea no mesmo doente

dos doentes foram diagnosticados os dois tipos de lesões ósseas. No grupo de doentes com os dois tipos de lesões ósseas, 20\% foram diagnosticados com neoplasia da próstata e $20 \%$ com neoplasia da mama.

Foi comparada a taxa de mortalidade durante 0 internamento e no follow-up após um ano entre doentes com neoplasias com elevada taxa de metastização (mama, pulmão e próstata) e os restantes tipos de neoplasias. Não se verificou maior taxa de mortalidade nos doentes afectados com neoplasias com maior metastização (falecidos 7 doentes com neoplasia com maior metastização e 7 doentes com as restantes neoplasias).

Em termos de abordagem diagnóstica, foi realizada biópsia óssea em 10 doentes. Em 22\% dos doentes sem diagnóstico prévio não se identificou a neoplasia primária. Constatou-se que a taxa de mortalidade durante 0 internamento foi de $14 \%$, e no follow-up após um ano de $21 \%$. A taxa de mortalidade durante 0 internamento nos doentes com neoplasia primária conhecida foi superior (21\%) à do grupo de neoplasia oculta (11\%), contrariamente ao follow-up.

\section{Discussão}

A metastização óssea constitui uma causa de elevada morbimortalidade em doentes com neoplasia ${ }^{6}$. 0 mecanismo responsável pelo crescimento das neoplasias ósseas é complexo e envolve a interação entre osteoclastos e osteoblastos, assim como a resposta do microambiente 2 . 0 mecanismo responsável pela formação de lesões líticas ou blásticas permanece desconhecido, apesar de diversos es- 
tudos recentes que demonstram alguns progressos para a sua compreensão $0^{7}$.

A neoplasia da mama constitui o protótipo de tumor precursor de lesões osteolíticas, dada a produção de factores que estimulam a osteólise 2 . Para além deste tipo de neoplasia, 0 tumor do pulmão e da tiróide são também responsáveis por lesões osteolíticas secundárias ${ }^{8,9}$. 0 tumor da próstata apresenta propensão para metastizar para 0 osso, provocando uma disrupção na estrutura óssea e alteração na remodelação. Apesar de se caracterizarem como tipicamente blásticas, as metástases ósseas associadas ao tumor da próstata provocam alteração na reabsorção e formação óssea. A produção de factores de crescimento tumoral nesta neoplasia está associada às alterações blásticas verificadas ${ }^{2}$. No grupo de doentes analisados, as lesões osteolíticas verificaram-se sobretudo nos doentes com neoplasia do pulmão e próstata, e em menor número na neoplasia da mama. Este facto pode ser justificado pelo Hospital Geral não apresentar valência de Ginecologia, onde serão avaliadas de forma continuada as mulheres diagnosticadas com neoplasia da mama. Por outro lado, a percentagem razoável de doentes com neoplasia da próstata e lesões líticas, apesar de contraditória à larga maioria dos estudos, não é de todo nova, permanecendo no entanto dúbia e sem esclarecimento completo ${ }^{3}$. Até agora, a teoria mais comprovada será a da presença de PTHrP e o seu receptor nas metástases ósseas líticas na neoplasia da próstata 3 .

Segundo diversos estudos, os locais mais frequentemente afectados por metastização óssea são a coluna vertebral, seguidos pela grelha costal e ossos da bacia, pelas suas características de elevada vascularização $0^{3,7,9}$. 0 estudo efectuado está de acordo com esta referência, sendo o principal local de metastização a coluna vertebral nos doentes avaliados. As diversas modificações celulares e de regeneração provocam a disrupção da formação trabecular, que se associa por sua vez a fracturas das costelas e colapso vertebral ${ }^{10}$. Diversos estudos demonstraram que a região torácica da coluna vertebral foi a mais envolvida na metastização. 0 pulmão e a mama metastizam preferencialmente para a região torácica, devido à drenagem venosa da mama através da veia ázigos e do pulmão através das veias pulmonares ${ }^{3}$. A neoplasia da próstata metastiza sobretudo para a região lombar e pélvis. No estudo efectuado, a metastização a nível da coluna vertebral estava sobretudo associado à neoplasia do pulmão e da próstata. Este facto pode-se dever, mais uma vez, ao não seguimento no pólo hospitalar de doentes com patologia ginecológica e assim, neoplasia da mama.

A metastização óssea constitui a causa mais frequente de dor nos doentes com cancro ${ }^{3}$. A metastização da coluna vertebral pode provocar dor, instabilidade e alterações neurológicas. Assim, tal como seria de esperar, no estudo verificou-se que as principais queixas dos doentes eram as lombalgias e paraplegia dos membros inferiores.

A presença de metástases ósseas é associada a um mau prognóstico, com apenas 20\% dos doentes com tumor da mama com metastização óssea a apresentar sobrevida aos 5 anos. Em diversos estudos, verifica-se também a elevação da taxa de mortalidade a um ano em doente com neoplasia da próstata com metastização óssea comparativamente em doentes sem metastização $0^{11}$.

A sobrevida em doente com neoplasia primária conhecida mostra-se superior, em muitos estudos e de uma forma geral, comparativamente às neoplasias de origem indeterminada. No entanto, existem alguns tumores, que pelas suas características particularmente agressivas, apresentam um pior prognóstico comparativamente aos tumores de origem indeterminada, sendo eles o tumor do pâncreas, estômago e fígado $^{5}$. No estudo efectuado, verifica-se que a mortalidade à data de alta do internamento em doentes com neoplasia conhecida é superior do que em doentes com neoplasia indeterminada, o que não se verifica no follow-up a um ano. Pode considerar-se que os doentes com neoplasia previamente conhecida podem apresentar metastização óssea mais tardia, e assim, com pior prognóstic $0^{5}$.

\section{Conclusões}

A metastização óssea resulta de uma complexa associação entre as células do tumor nativo e o microambiente do osso, que conduz a diferentes tipos de lesões. 0 estudo realizado encontra-se de acordo com os vários estudos publicados no que se refere à prevalência de metastização para a coluna vertebral e grelha costal. Contrariamente ao descrito maioritariamente na literatura, verificou-se uma maior incidência de lesões líticas na neoplasia da próstata.

A disseminação tumoral com expressão através da metastização relaciona-se com um agravamento do prognóstico no follow-up. A importância da deteção precoce prende-se com a melhoria do outcome e a possibilidade de terapêuticas mais agressivas com melhor prognóstico.

\section{Referência}

1. Li S, Peng Y, Weinhandl ED, Blaes AH, Cetin K, Chia VM, Stryker S, Pinzone JJ, Acquavella JF, Arneson TJ. Estimated number of prevalent cases of metastatic bone disease in the US adult population. Clin Epidemiol 2012; 4: 87-93;

2. Guise TA, Mohammad KS, Clines G, Stebbins EG, Wong DH, Higgins LS, et al. Basic mechanisms responsible for osteolytic and osteoblastic bone metastases. Clin Cancer Res. 2006; 12:6213-16;

3. Maccauro G, Spinelli MS, Mauro S, Perisano C, Graci C, Rosa MA. Physiopathology of spine metastasis. Int J Surg Oncol 2011; 2011: 107969;

4. Molloy AP, O'Toole GC. Orthopaedic perspective on bone metastasis. World J. Orthop. 2013 Jul 18; 4(3): 114-119;

5. Jihimäki M, Thomsen H, Hemminki A, Sundquist K, Hemminki K. Comparison of survival of patients with metastases from known versus unknown primaries: survival in metastatic cancer. BMC Cancer 2013,13:36;

6. Camacho DF, Pienta KJ. A multi-targeted approach to treating bone metastases. Cancer and Metastasis Rev. 2014 Sep;33(2-3):545-53;

7. Käkönen SM, Mundy GR. Mechanisms of osteolytic bone metastases in breast carcinoma. Cancer 2003, 97: 834-839;

8. Riccio Al, Wodajo FM, Malawer M. Metastatic carcinoma of the long bones. Am Fam Physician 2007, 76:1489-1494.

9. Kakhki VR, Anvari K, Sadeghi R, Mahmoudian AS and Torabian-Kakhki M. Pattern and distribution of bone metastases in common malignant tumors. Nucl Med Rev Cent East Eur 2013, 16: 66-69;

10. Coleman, R et al. Management of bone metastases. Oncologist 2000, 5: 463-470;

11. Patel LR, Camacho DF, Shiozawa Y, Pienta KJ, Taichman RS. Mechanisms of cancer cell metastasis to the bone: a multistep process. Future Oncol. 2011; 7(11):128597. 